\title{
Interstitial expansion in health and disease - an equilibrium contrast CMR study
}

\author{
Daniel Sado ${ }^{1,2^{*}}$, Andrew Flett ${ }^{1}$, Steven K White ${ }^{1}$, Sanjay M Banypersad ${ }^{1,4}$, Viviana Maestrini ${ }^{1}$, Atul Mehta ${ }^{3}$, \\ Philip N Hawkins ${ }^{4}$, Derek J Hausenloy ${ }^{1}$, Perry Elliott ${ }^{2}$, James Moon ${ }^{1}$ \\ From 15th Annual SCMR Scientific Sessions \\ Orlando, FL, USA. 2-5 February 2012
}

\section{Summary}

In this study of 278 particiapnts, we aimed to evaluate the cardiac interstitium in health and disease using Equilibrium constrast CMR (EQ-CMR). We found gender and disease differences in the contrast myocardial volume of distribution $\mathrm{Vd}(\mathrm{m})$ and correlations with clinical CMR markers of disease.

\section{Background}

Interstitial myocardial volume expansion is an important factor in cardiac disease but until recently could only be accurately assessed with biopsy. We used a new method, EQ-CMR, to accurately quantify the interstitium across a wide spectrum of cardiac diseases.

\section{Methods}

The three steps in EQ-CMR are: 1) a primed gadolinium infusion to achieve contrast equilibrium, 2) Signal (T1) measurement pre and post equilibrium, 3) measurement of blood contrast volume (1- haematocrit). This allows calculation of $\mathrm{Vd}(\mathrm{m})$ by:

$\mathrm{Vd}(\mathrm{m})=(1$-hematocrit $)$ x $\Delta(1 / \mathrm{T} 1)$ myo $\div \Delta(1 / \mathrm{T} 1)$ blood.

$\mathrm{Vd}(\mathrm{m})$ was measured in 278 subjects: 86 normal subjects (median age 43, range 24 to $81,51 \%$ male) and 192 patients with Anderson-Fabry disease (AFD, $n=17$ ), dilated cardiomyopathy (DCM, $\mathrm{n}=31$ ), hypertrophic cardiomyopathy (HCM, $n=31$ ), severe aortic stenosis (AS, $\mathrm{n}=66$ ), cardiac amyloidosis $(\mathrm{n}=27)$ or myocardial infarction (MI, $\mathrm{n}=20$ ).

\section{Results}

In normal subjects, mean $\mathrm{Vd}(\mathrm{m})$ was higher in females $(0.274)$ than males $(0.237, \mathrm{P}<0.001)$. In all diseases, $\mathrm{Vd}$

${ }^{1}$ Imaging Centre, The Heart Hospital, London, UK

Full list of author information is available at the end of the article (m) was higher than normal subjects $(\mathrm{P}<0.001)$ except the intracellular storage disease AFD $(0.250, \mathrm{P}=0.9)$. Vd $(\mathrm{m})$ was the same in DCM (0.280), HCM (0.291) and AS (0.276), but higher in the exemplar of infiltrative disease, cardiac amyloidosis (0.466) and higher again in MI (0.585, each $\mathrm{P}<0.001)$, (figure). These trends were also present when disease data was compared to gender matched normal subjects. Where $\mathrm{Vd}(\mathrm{m})$ was elevated, correlations existed with clinical CMR parameters such as ejection fraction and septal thickness in apparent disease specific patterns, (table).

\section{Conclusions}

This preliminary study suggests that $\mathrm{Vd}(\mathrm{m})$ is a potentially important new biomarker across the spectrum of health and cardiac disease.

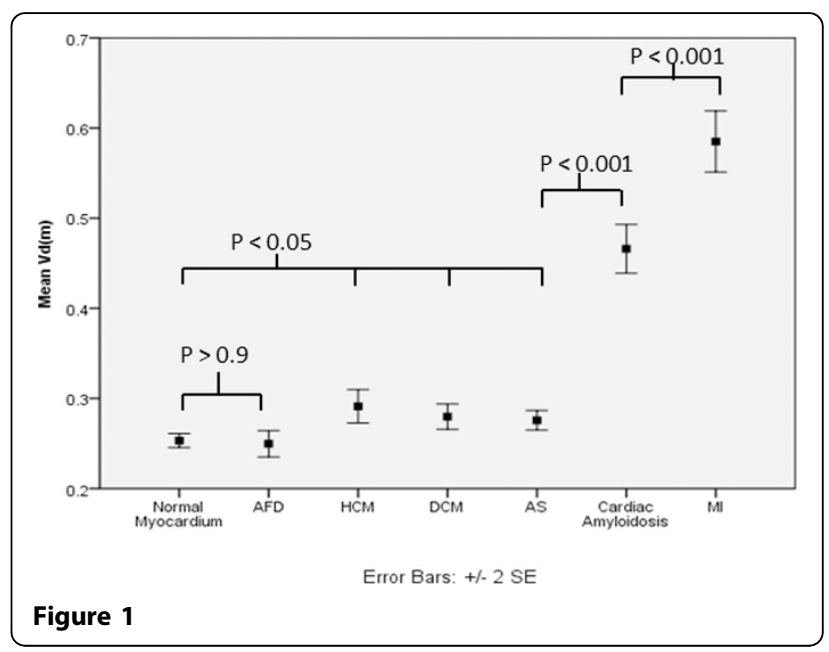

\section{C) Biomed Central}

(c) 2012 Sado et al; licensee BioMed Central Ltd. This is an open access article distributed under the terms of the Creative Commons Attribution License (http://creativecommons.org/licenses/by/2.0), which permits unrestricted use, distribution, and reproduction in any medium, provided the original work is properly cited. 
Table 1 Pearson Correlations between $\mathrm{Vd}(\mathrm{m})$ and CMR markers of disease

\begin{tabular}{|c|c|c|c|c|c|c|}
\hline Disease & $\mathrm{EF}$ & $\mathrm{EDV}(\mathrm{i})$ & ESV(i) & Mass(i) & Left Atrial Area (i) & Other \\
\hline Normal Subjects & NS & NS & NS & $R=-0.36^{* *}$ & NS & None \\
\hline AFD & NS & NS & NS & NS & NS & None \\
\hline DCM & $R=-0.35^{*}$ & NS & NS & $R=-0.36^{*}$ & $R=0.65^{* * *}$ & None \\
\hline AS & NS & NS & $\mathrm{R}=0.51^{*}$ & NS & NS & Aortic Valve Area: $\mathrm{R}=-0.41^{* *}$ \\
\hline $\mathrm{HCM}$ & NS & NS & NS & NS & NS & LGE\%: $R=0.48^{*}$ \\
\hline Cardiac Amyloidosis & $R=-0.57^{* *}$ & NS & $R=0.63^{* * *}$ & $R=0.44^{*}$ & NS & Septal Thickness: $R=0.51^{* *}$ \\
\hline
\end{tabular}

Key: NS: No significant correlation; ${ }^{*} p<0.05 ;{ }^{* *} p<0.01 ;{ }^{* *} p<0.001$

\section{Funding}

1) The British Heart Foundation (Cardiomyopathy, Myocardial Infarction, Aortic Stenosis and Normal Subjects).

2) Genzyme Coorporation (Anderson Fabry Disease).

3) GlaxoSmithKline (Amyloidosis and Normal Subjects).

\section{Author details}

${ }^{1}$ Imaging Centre, The Heart Hospital, London, UK. ${ }^{2}$ Inherited Cardiac Disease, The Heart Hosptial, London, UK. ${ }^{3}$ Lysosomal Disorderds Unit, The Royal Free Hospital, London, UK. ${ }^{4}$ Amyloidosis, National Amyloidosis Centre, London,

UK.

Published: 1 February 2012

doi:10.1186/1532-429X-14-S1-O23

Cite this article as: Sado et al:: Interstitial expansion in health and disease - an equilibrium contrast CMR study. Journal of Cardiovascular Magnetic Resonance 2012 14(Suppl 1):O23.

Submit your next manuscript to BioMed Central and take full advantage of:

- Convenient online submission

- Thorough peer review

- No space constraints or color figure charges

- Immediate publication on acceptance

- Inclusion in PubMed, CAS, Scopus and Google Scholar

- Research which is freely available for redistribution

Submit your manuscript at www.biomedcentral.com/submit 